\title{
Ethical Considerations of the Human Research: Syphilis Experiments and Denial of Drug Therapy
}

\section{Esther Cuerda ${ }^{1}$ and Francisco López-Muñoz ${ }^{2,3,4 *}$}

${ }^{1}$ Department of Anatomy, Rey Juan Carlos University, Madrid, Spain ${ }^{2}$ Faculty of Health Sciences, Camilo José Cela University, Madrid, Spain ${ }^{3}$ Department of Pharmacology, University of Alcalá, Madrid, Spain

4"Hospital 12 de Octubre" Research Institute, Madrid, Spain

Syphilis has historically been considered a special disease as sexually transmitted disease and because no effective treatments were disposable for years. At the end of XV century first cases were reported and until beginning of XX century not scientific advances were made: Schaudinn and Hoffmann discovered the germ which caused disease in 1905 (Treponema pallidum) and few years later serological test for diagnoses were developed. Fleming had discovered penicillin in 1928 but it was not used in medical practice before World War II (WWII). Military physicians from United States used penicillin for treating syphilis in Pacific troops in December 1943 [1]. Treatment was successful and in 1947 penicillin had become the standard treatment for syphilis. Before it, syphilis was a multisystemic, chronic, painful and deadly disease. Due to penicillin, prospects changed radically. The successful was such as in middle 50's incidence of syphilis was so low that many scientists believed that syphilis would be soon eradicated [2].

Once efficacy of treatment was established, any patient affected from syphilis should be treated with penicillin. However, numerous researches were performed on which, deliberately, patients did not receive any treatment just for studying disease spreads and they were even inoculated with syphilis to determine optimum treatment doses. In other cases treatment was not administered, even when infected patients could transmit the disease to their sexual partners and descendants. We comment three examples that illustrate this unethical approach.

1. The first case took place in United States prisons in 1940s. The use of inmates for researching proposes was common in US from years ago: as an example in San Quintin prison, experiments where testes from dead inmates or animals were implanted to prisoners had been carried out [3]. Some years after WWII and Nuremberg Code promulgation, researches continued in prisons arguing that inmates were volunteers. It is difficult to affirm that a prisoner was involved as volunteer in an experiment where his testicles were irradiated until his sterilization (Oregon, Washington, during 50's), or when dioxins were applied over his skin until non-reversible lesions were produced (Holmesburg, Pennsylvania, 1940-1974). Experiments with syphilis found a place in this political, ethical, social, working and scientific environment. Syphilis researches were performed for years using inmates of Sing Sing prison in New York [4], where they were deliberately inoculated with Treponema pallidum. Infected prisoners received treatment with arsenicals, even when penicillin has shown to be more effective than arsenicals [5]; other times they received noneffective doses of penicillin.

2. Second case took place too in US. Tuskegee experiment consisted of a non-therapeutically long-term research to study natural spread of syphilis where effective treatment was denied to hundred of Afro-Americans males from Alabama [6,7] and performed by US Public Health Service (USPHS). Its aim was to determine the disease progress in non-treated patients. It was carried out in a rural, uncultivated and poor social stratum and it was not interrupted even when effective treatments as penicillin were introduced for treating disease.

The Tuskegee experiment took place from 1932 to 1972. Most of their participants died from syphilis during the long-term study (40 years) and there were newborns affected from congenital syphilis, with the impassive of physicians involved in the study. Tuskegee experiment has been qualified as the most infamous biomedical research in US [8], and resulted in the Belmont Report about bioethics.

In early XX century, it was commonly accepted that tertiary syphilis affected preferentially Central Nervous System (CNS) in those Caucasian patients meanwhile cardiovascular involvement was more frequent in Afro-Americans ones. In 1928, a study performed in Oslo was published in which the authors reported more cardiovascular than CNS involvement in Caucasian males [9]. It was a retrospective study with data collected from syphilitic patients who did not receive any treatment [10].

Researches decided to perform a similar study in the US in Macon, an Alabama's county with high prevalence of syphilis. According to preliminary data, more than $35-40 \%$ of all age group had positive serology for syphilis. Taliaferro Clark proposed an observational study with syphilitic non-treated patients for 6-8 months and treated them after it with the standard therapeutic schema (Salvarsan and Bismuth) [11]. In 1932 a group of 600 Afro-Americans men was selected; 399 suffered from syphilis and 201 were not infected. Study participants, most of them illiterate, received free medical assistance, a daily meal and a burial insurance. They were not informed that they suffered from syphilis neither were treated. The men were told that they had "bad blood", a local and popular term which included anemia, weakness or syphilis [10].

Ethical considerations were not taken into account. Not only patients involved were not informed, but even they were misleading to have their collaboration. A trick letter titled Last Chance for Special Free Treatment was send to participants to make them a cerebrospinal fluid test. Patients were insisted to authorize their autopsy after death

*Corresponding author: Dr. Francisco López-Muñoz, Faculty of Health Sciences, Camilo José Cela University, C/ Castillo de Alarcón, 49, Urb. Villafranca del Castillo, 28692 Villanueva de la Cañada, Madrid, Spain, Tel: +34 91815 3131; Fax: +34 91 860 9343; E-mail: francisco.lopez.munoz@gmail.com

Received October 21, 2013; Accepted October 24, 2013; Published October 31 2013

Citation: Cuerda E, López-Muñoz F (2013) Ethical Considerations of the Human Research: Syphilis Experiments and Denial of Drug Therapy. Clin Exp Pharmacol 3: e124. doi:10.4172/2161-1459.1000e124

Copyright: $\odot 2013$ Cuerda E, et al. This is an open-access article distributed under the terms of the Creative Commons Attribution License, which permits unrestricted use, distribution, and reproduction in any medium, provided the original author and source are credited. 
to receive their burial insurance. Study was not secret. First clinical data obtained from the Tuskegee experiments were published in 1934, and first report was in 1936. Numerous data and manuscripts were published during the experiment [12-15]. Treatment with penicillin was deliberately denied. Many patients received placebo and even they were advised to avoid use of penicillin that was used for treating other patients. Researches requested that local physicians withhold treatment from study subjects and followed the men until death. The US military and USPHS combated sexually transmitted diseases through an allout campaign of research, treatment program and advertising, but Tuskegee Group was carefully avoid. During WWII, 250 participants were enlisted. As serological test was performed to the soldiers, Tuskegee men were diagnosed of syphilis. Researchers kept the men from receiving treatment ordered by the military draft.

In 1945, although accepted as the drug of choice for syphilis, researches decided not to treat the men with penicillin and continue the study until their death. In 1968 a venereal disease investigator named Peter Buxtum working in the USPHS, warned against the study but Centers for Disease Control and Prevention (CDC) and the authorities reaffirmed their support for the study. In 1972, Buxtun informed the press and the study was published in local newspapers. Public opinionmore than ethical or moral considerations- lead to cancel the study. Tuskegee lasted 40 years. At the end of the study only 74 patients involved were still alive. From the 399 infected group: 28 were dead from syphilis and 100 more from medical complication related to syphilis.

3. Third case was in Guatemala, where practitioners from US, with local support from government, administration and physicians performed syphilis experiments from 1946 to 1948. For more than 2 years, semi clandestine experiments were performed in Guatemala, involving more than 1000 people (soldiers, prisoners, mental ill patients and prostitutes) without consent [16]. Physicians inoculated deliberately 1,308 adults with syphilis, chancroid and gonorrhea, using in some cases infected prostitutes to infect inmates and soldiers [17]. Even when scientists had demonstrated in 1943 that penicillin was effective for treat syphilis and gonorrhea and it was the treatment choice for syphilis from 1945, prevention and treatment of disease were not clear. During WWII, army physicians from all countries (US, Europe or Japan) noticed that sexually transmitted diseases were a common health problem in their troops. Military doctors were interested on finding prophylactics treatments to avoid spread in soldiers. After sex, service-men were supposed to inject a solution containing silver into their penises to prevent gonorrhea, and rub a calomel ointment over their genitals to prevent syphilis, but these methods were not comfortable and they were painful and poorly effective.

Doctors from US commenced a research in a prison located in Terre Haute, Indiana, using volunteer inmates as experimental guinea pigs, inoculating them with syphilis [18]. The experiment was cancelled some time later by unknown reasons. After Terre Haute experiments, the researches designed a more ambitious experiment: they wanted to infect normal population with prostitutes, but they were consciousness that an experiment like that could not be performed in US. Authorities involved in design and development of experiment were VDRL (Venereal Diseases Research Lab), USPHS, which became into CDC all of them supported by Guatemalan researches [19] and PASB (Pan American Sanitary Bureau).
The main researcher was the US doctor John C. Cutler, under supervision of Richard C. Arnold and John F. Mahoney, members of USPHS and VDRL. They collaborated in Guatemala with Dr. Juan Manuel Funes, Chief of Venereal Disease Control Division (Public Health Authority of Guatemala), and were supported by functionaries from Health Ministry and Army, and with collaboration of functionaries of Ministries of Health, Interior and Defense of Guatemalan Government.

Why in Guatemala? One of more influent factors was the actual regulation where prostitution was legal and sexual workers were allowed to perform their services in prisons. Firstly experiments were started in prisons but results inoculating inmates by prostitutes infected previously by Treponema cultured in lab animals, were not satisfactory. More prisoners refused the periodical blood tests that lead to incomplete serological following. These were the reasons because study design and target population were changed: now mental illness interned in the National Mental Health Hospital were used. These patients had the great advantage that by their mental condition not refused the experiments. In the hospital, patients were inoculated by scarification, subcutaneous injection, urethral inoculation or injection in liquid fluid. Prostitutes were not allowed in hospitals.

Guatemalan experiments consisted in deliberately inoculate not only with syphilis but other sexually transmitted diseases such as gonorrhea and chancroid in people from not valued strata and without autonomy: soldiers, inmates, prostitutes and mental illness. Some of the researches were performed with orphans in the Hospice National and scholars in Puerto de San José $[20,21]$. In most of cases patients were treated with penicillin to compare effectiveness and control serological changes.

Study was concluded in 1948 although some lab tests or even autopsies in 1958 were performed years later. As the same that in Tuskegee experiment, results were published for example in the II Congreso Centro-Americano de Venereología, held in Guatemala City, in April 1948 or in the journal Salubridad y Asistencia, informative organ of the Ministry of Health and Social Welfare, Volume II, Numbers 4-7 (April-July 1949).

In 2010, a casual finding of the related documents by a historian who researched in Tuskegee experiments came to light. Alter declassification of files and posterior analyses, chronology of experiments has been detailed. Cutler's files related to Guatemala case are in Pittsburgh University available for consulting. They include extended reports of syphilis researches and shorter of gonorrhea and chancroid, letters, experimental and clinical data and list of patient's names.

Some years later Nuremberg Trial, where Nazi doctors were judged by atrocities committed during WWII and ethical codes were established [22], human researches out of ethical limits have took place again. The causes are varied, some collective and some individual: most of US doctors believed that Nuremberg Code was not applicable for themselves because circumstances had changed and their experiments were not comparable to the atrocities committed by their Nazi colleagues. Other adduced that although medium used were not absolutely ethical, the purpose (determine the best therapeutic option, the best serological test, etc.,) justified all precedent. We cannot forget personal interest of involving doctors of publishing and notoriety, forgetting the Hippocratic Oath Maximum Primun non nocere. Experimentation and scientific researches cannot be over the humanization of healthcare profession, which main purpose is alleviating patient's suffering. But, will we be able to learn this lesson? 
Citation: Cuerda E, López-Muñoz F (2013) Ethical Considerations of the Human Research: Syphilis Experiments and Denial of Drug Therapy. Clin Exp Pharmacol 3: e124. doi:10.4172/2161-1459.1000e124

\section{References}

1. Mahoney JF, Arnold RC, Harris AD (1943) Penicillin Treatment of Early Syphilis: A Preliminary Report. Venereal Dis Inf 24: 355-357.

2. Quétel C (1986) Le Mal de Naples: Histoire de la Syphilis. Ed Seghers, Paris.

3. Stanley LL (1922) An analysis of one thousand testicular substance implantations. Endocrinology 6: 787 7788 .

4. Magnuson HJ, Thomas EW, Olansky S, Kaplan BI, De Mello L, et al. (1956) Inoculation syphilis in human volunteers. Medicine (Baltimore) 35: 33-82.

5. Kaplan BI, Ryan J, Thomas E, Cutler JC, Jones O (1958) Results of therapy of latent and asymptomatic syphilis in a prison population. II. Seroreversa following definitive treatment as shown by the New York State complement fixation test. J Chronic Dis 7: 312-320.

6. Harter LM, Stephens RJ, Japp PM (2000) President Clinton's Apology for the Tuskegee Syphilis Experiment: A Narrative of Remembrance, Redefinition, and Reconciliation. Howard J Comm 11: 19-34.

7. Carmack HJ, Bates BR, Harter LM (2008) Narrative constructions of health care issues and policies: the case of President Clinton's apology-by-proxy for the Tuskegee syphilis experiment. J Med Humanit 29: 89-109.

8. Katz RV, Kegeles SS, Kressin NR, Green BL, Wang MQ, et al. (2006) The Tuskegee Legacy Project: willingness of minorities to participate in biomedical research. J Health Care Poor Underserved 17: 698-715.

9. Gjestland T (1955) The Oslo study of untreated syphilis; an epidemiologic investigation of the natural course of the syphilitic infection based upon a restudy of the Boeck-Bruusgaard material. Acta Derm Venereol Suppl (Stockh) 35: 3-368.

10. Jones J (1981) Bad Blood: The Tuskegee Syphilis Experiment. A Tragedy of Race and Medicine. The Free Press, New York.

11. Sierra X (1993) Historia de las enfermedades de transmisión sexual. In Vilata JJ, Enfermedades de transmisión sexual. Prous Editores, Barcelona: 1-18.
12. Olansky S, Simpson L, Schuman SH (1954) Environmental factors in the Tuskegee study of untreated syphilis. Public Health Rep 69: 691-698.

13. Schuman SH, Olansky S, Rivers E, Smith CA, Rambo DS (1955) Untreated syphilis in the male negro; background and current status of patients in the Tuskegee study. J Chronic Dis 2: 543-558.

14. Rockwell DH, Yobs AR, Moore MB Jr (1964) The tuskegee study of untreated syphilis; the 30th year of observation. Arch Intern Med 114: 792-798.

15. Caldwell JG, Price EV, Schroeter AL, Fletcher GF (1973) Aortic regurgitation in the Tuskegee study of untreated syphilis. J Chronic Dis 26: 187-194.

16. Semeniuk I, Reverby S (2010) A shocking discovery. Nature 467: 645

17. Tanne JH (2010) President Obama apologises to Guatemala over 1940s syphilis study. BMJ 341: c5494.

18. Walter M (2012) Human experiments: First, do harm. Nature 482: 148-152.

19. Funes JM, Cutler JC, Levitan S, Portnoy J, Funes R (1953) [Serologic and clinical studies of syphilis in Guatemala, Central America. II. Study of a group of school children in the port of San José]. Bol Oficina Sanit Panam 34: 14-18.

20. Levitan S, Aragon HA, Cutler JC, Funes JM, Portnoy J, et al. (1952) Clinical and serologic studies with reference to syphilis in Guatemala Central America I. Studies of comparative performance of the Kahn, Kolmer, Mazzini, and VDRL slide tests as carried out in the national orphanage. Am J Syph Gonorrhea Vener Dis 36: $379-387$.

21. Levitan S, Aragon HA, Cutler JC, Funes JM, Portnoy J, et al. (1952) Clinica and serologic studies with reference to syphilis in Guatemala Central America. I. Studies of comparative performance of the Kahn, Kolmer, Mazzini, and VDRL slide tests as carried out in the national orphanage. Am J Syph Gonorrhea Vener Dis 36: 379-387.

22. López-Muñoz F, Alamo C, Dudley M, Rubio G, García-García P, et al. (2007) Psychiatry and political-institutional abuse from the historical perspective: the ethical lessons of the Nuremberg Trial on their 60th anniversary. Prog Neuropsychopharmacol Biol Psychiatry 31: 791-806. 